\title{
COMISSÃO DA VERDADE: OS DOCUMENTOS E A VALIDEZ DO DISCURSO
}

\section{COMISIÓN DE LA VERDAD: LOS DOCUMENTOS Y LA VALIDEZ DEL DISCURSO}

\author{
Dayo de Araujo Silva Côrbo - dayocorbo@gmail.com \\ Mestre em Ciência da Informação no Instituto Brasileiro de \\ Informação em Ciência e Tecnologia (IBICT). Bibliotecária do \\ Arquivo Nacional.
}

Clóvis Ricardo Montenegro de Lima - clovis.mlima@uol.com.br Pós-doutor em Ciência da Informação pelo Instituto Brasileiro de Informação em Ciência e Tecnologia (IBICT). Pesquisador adjunto do IBICT.

\section{RESUMO}

Introdução: O presente artigo fundamenta-se na dissertação de mestrado, Comissão da Verdade: os documentos e a validez do discurso, defendida no Instituto Brasileiro de Informação em Ciência e Tecnologia no ano de 2013, tem como objetivo investigar o papel da informação, materializada em documentos, a partir da ação de atores sociais que agem comunicativamente e que produzem aprendizagem ao agirem.

Objetivo: Investigar o papel da informação, materializada em documentos, a partir da ação dos atores sociais que agem comunicativamente e que produzem aprendizagem ao agirem. Utiliza-se como objeto de investigação a Comissão Nacional da Verdade do Brasil.

Metodologia: A metodologia empregada é uma pesquisa descritiva e exploratória. Usa-se como referencial teórico a reformulação de uma versão discursiva da verdade feita por Jürgen Habermas com fins de sanar o problema da ineficácia da teoria da verdade por correspondência.

Resultados: Nessa teoria o conceito de verdade compara-se a uma assertividade ideal e é atributo dos enunciados.

Conclusões: A partir da teoria pragmática da verdade evidencia-se, no objeto de estudo, que a informação em atos de fala e na sua materialização documental atua como uma verdade provisória que se valida no discurso público.

Palavras-chave: Habermas. Comissão da Verdade. Informação. Documento. Verdade. Discurso. 


\section{INTRODUÇÃO}

O presente artigo fundamenta-se na dissertação de mestrado, Comissão da Verdade: os documentos e a validez do discurso, defendida no Instituto Brasileiro de Informação em Ciência e Tecnologia no ano de 2013, tem como objetivo investigar o papel da informação, materializada em documentos, a partir da ação de atores sociais que agem comunicativamente e que produzem aprendizagem ao agirem.

O atual debate sobre a Comissão Nacional da Verdade do Brasil se insere em um grande arcabouço de temas comuns às novas democracias da América Latina. Esses temas incluem: definir de que modo e por que meios averiguar e confrontar 0 conhecimento do que aconteceu no passado, como chegar a uma versão consensual da verdade, como fazer com que os envolvidos nas violações de direitos humanos possam ser legalmente responsabilizados pelas ações cometidas no passado, qual a responsabilidade do Estado e como este poderia se redimir diante das vítimas.

Este arcabouço de temas não se desassocia dos estudos da informação em especial do papel da informação no processo de aprendizagem produzida pela ação de atores sociais que agem orientados pela verdade. Nesse sentido, no presente artigo analisa-se a partir da reformulação do conceito de verdade na teoria de Habermas, a relação entre a informação e a aprendizagem no âmbito das comissões da verdade, destacando-se as informações dos atos de fala e dos documentos.

Habermas (2002) afirma que a aprendizagem está ligada às atividades intramundanas e não em uma forma subjetiva transcendental, por este motivo reformula a idéia transcendental kantiana, a partir da intuição de Humboldt, de que no processo de comunicação lingüística está em ação uma força sintética capaz de estabelecer uma unidade na multiplicidade por meio do diálogo.

Sendo assim, no lugar da perspectiva fundadora da unidade, na qual, o sujeito aplica de um lado, os processos sensitivos, e de outro as experiências vividas, fazendo uso do entendimento individual transcendental, é posto a diferença entre as perspectivas, a partir das quais os participantes da comunicação chegam a um entendimento entre si, sobre algo no mundo. Essas perspectivas de falantes e ouvintes não confluem mais no centro de uma subjetividade centrada em si mesma, elas se entrelaçam no centro da linguagem.

Nessa abordagem, a linguagem constitui uma totalidade constituída de um sistema de regras. A linguagem possibilita a prática da ação comunicativa entre os sujeitos que 
pertencem a uma mesma comunidade lingüística, por meio da qual se mantém como sistema e se renova. O interesse de Humboldt, segundo Habermas (2002), estaria na força que estabelece a unidade a partir da diferença entre as perspectivas a partir das quais os participantes de uma comunicação chegam a um entendimento entre si sobre a mesma coisa.

\begin{abstract}
O interesse de Humboldt dirige-se principalmente para um fenômeno: no processo de comunicação lingüística está em ação uma força sintética capaz de estabelecer a unidade na multiplicidade, porém, através de um novo caminho, que não é mais o da subsunção da variedade sob uma regra geral. [...] Humboldt substitui o conceito construtivista de síntese através do conceito da união pacífica do diálogo (HABERMAS, 2002, p. 196).
\end{abstract}

Com isso, a racionalidade se mantém na história natural e social dos seres humanos e está engastada numa pluralidade de linguagens naturais. Estando assim em um mundo da vida compartilhado por atores sociais que agem orientados pela verdade e visando o entendimento.

A partir dessa abordagem da aprendizagem, enfatizamos nossa perspectiva para o papel da informação, tendo como pano de fundo a busca de uma versão consensual da verdade no âmbito das comissões da verdade e da esfera pública. Utilizamos como aporte teórico à reformulação do conceito de verdade de Habermas. Entretanto, antes da ênfase nas versões teóricas da verdade de Habermas, discorremos sobre o conceito de Comissão da Verdade a partir do processo de instauração da Comissão Nacional da Verdade do Brasil.

\title{
2 A COMISSÃO NACIONAL DA VERDADE E SUAS CONTROVÉRSIAS
}

A instauração da Comissão Nacional da Verdade do Brasil, como em outras comissões formadas na América Latina, é fruto de antigas reivindicações de atores da sociedade civil, em especial, dos parentes de vítimas do regime ditatorial. O debate sobre a instauração desta Comissão gerou grandes divergências na esfera pública e política, quanto aos termos utilizados para evidenciar o trabalho da Comissão, a data de abrangência da investigação e na questão da validação da Lei de Anistia. Essas divergências não fogem do tema da informação, sobretudo, da questão do acesso às fontes de informação que remetem ao período investigado pela Comissão. 
Com isso, constata-se que a primeira proposta de criação da Comissão Nacional da Verdade foi estabelecida no $3^{\circ}$ Programa Nacional de Direitos Humanos, neste evento apresentou-se um conjunto de leis sugeridas pelo então presidente Luiz Inácio Lula da Silva, em Dezembro de 2009. Entretanto, essa proposta foi precedida por outras iniciativas desse governo nas questões de memória e verdade, como a organização do projeto Arquivo da Intolerância e a criação da Comissão de Verdade e Justiça.

O projeto Arquivo da Intolerância foi criado com o objetivo de organizar os documentos sobre as prisões, os desaparecimentos, as torturas e as mortes durante 0 regime ditatorial. Sendo responsável também pela disponibilização irrestrita dessas fontes de informação à consulta pública. Nesse projeto chegou-se a criar uma comissão de averiguação e análise de informações sigilosas que requereu documentos às Forças Armadas e à Agência Brasileira de Inteligência (ABIN).

Contudo, esse projeto não obteve sucesso devido uma decisão do Tribunal Regional Federal (TRF) que visava proteger tais informações. O governo do presidente Fernando Henrique Cardoso (1995-2002), havia tentado revogar tal decisão, entretanto, esta atitude provocou reações tanto nos setores favoráveis do Exército que ofereceram ajuda principalmente com a questão da guerrilha do Araguaia, quanto nos opositores à abertura dos arquivos que reagiram midiaticamente com a queima de arquivos na base de Salvador. Além disso, houve "recusa do governo brasileiro em abrir seus documentos à consulta paraguaia, temendo ressuscitar ranços históricos relacionados à ação brasileira durante a Guerra do Paraguai, entre outros." (WINAND; BIGATÃO, 2012, p. 6).

A criação da Comissão Nacional da Verdade só iria entrar definitivamente na agenda política do governo Lula a partir de dezembro de 2008 quando foi encaminhada ao governo a orientação para que fosse constituída a Comissão de Verdade e Justiça, fruto dos debates da 11‥ Conferência Nacional de Direitos Humanos, que consolidou as discussões a respeito da revisão do Programa Nacional de Direitos Humanos.

Em 2009, destaca-se à palestra de abertura da Conferência Internacional sobre o Direito à Verdade, do então ministro da Secretaria Especial de Direitos Humanos, Paulo Vannuchi que ressaltava a importância de complementar o trabalho das Comissões Especial sobre Mortos e Desaparecidos Políticos e da Comissão de Anistia.

Constata-se ainda, no ano de 2009, um embate entre os ministros da Defesa, Nelson Jobim e dos Direitos Humanos, Paulo Vannuchi, enquanto que para o ministro da Defesa é inviável à revisão do acordo político que originou a Lei de Anistia de 1979, 
sendo o ministro contrário também à constituição de uma comissão com poderes para investigar e punir os que praticaram violações de direitos humanos. Para o ministro dos Direitos Humanos os crimes de violação de direitos humanos, de lesa-humanidade, não prescrevem. "Sendo assim, enquanto para Nelson Jobim, o nome da Comissão deveria ser "Comissão de Reconciliação" para Vannuchi, poderia apenas retirar a palavra "justiça" do nome original, 'Comissão da Verdade e Justiça'." (O ESTADO DE SÃO PAULO, 2009 apud WINAND; BIGATÃO, 2012, p. 7).

Estas controvérsias, entre os ministérios, ficaram explícitas em alguns trechos do documento que lançava o $3^{\circ}$ Programa Nacional de Direitos Humanos como, por exemplo, uma diretriz que se referia as violações de direitos humanos como "praticadas no contexto da repressão política" no período de 1964-1985, na interpretação do Ministério da Defesa e das Forças Armadas, a forma como foi escrito o documento, especificamente o termo "repressão política", previa apenas a apuração de violações praticadas pelos militares, excluindo-se os militantes da esquerda armada. Outra controvérsia é a proposta neste documento da criação de uma comissão especial para revogar a Lei de Anistia de 1979. Esta proposta é vista por Jobim e os militares como revanchista e provocativa.

Após quatro meses de negociações e ameaça de ambos os ministros de deixarem o cargo em 13 de maio de 2010 o presidente Lula apresenta o Projeto com as seguintes alterações: desapareceram as expressões "repressão ditatorial" e "perseguidos políticos"; a apuração das violações de direitos humanos perde o foco do período do regime militar, entre os anos1964-1988, para os anos 1946 a 1988.

Sendo assim, o projeto é enviado pelo presidente Lula ao Congresso Nacional contendo a instituição de uma Comissão Nacional da Verdade com a finalidade de examinar e esclarecer as graves violações de direitos humanos praticadas no período de 1946 a 1988 e citava que era dever dos servidores públicos civis e militares colaborar com a Comissão.

No governo da presidente Dilma Rousseff é aprovada a instauração da Comissão Nacional da Verdade, entretanto um dia antes da aprovação da lei que cria a Comissão da Verdade, outra lei que a complementa é aprovada no senado, a Lei de Acesso à Informação, que estabelece novas classificações aos documentos oficiais e sigilosos e prazos para torná-los públicos. 
A partir destes eventos precursores da instauração da Comissão Nacional da Verdade. Considera-se importante evidenciar no tocante a validação da Lei de Anistia, a interpretação de duas pessoas com notória participação na questão dos Direitos Humanos atualmente no Brasil. O secretário nacional dos Direitos Humanos e ministro da Justiça no governo de Fernando Henrique Cardoso, José Gregori e a atual secretária nacional dos Direitos Humanos, Flávia Piovesan.

Para Gregori (2012) a lei que criou a Comissão da Verdade é um marco político e institucional, porque o Brasil chegou a um consenso: houve desrespeito aos Direitos Humanos, e é preciso que uma Comissão oficial representativa cuide de esclarecê-lo. Porém, a respeito de punição, para o autor, a própria lei sancionada da Comissão da Verdade, afirma que "As atividades da Comissão Nacional da Verdade não terão caráter jurisdicional ou persecutório." (BRASIL, 2011). Ele justifica sua posição:

O peso da reverência a preceitos exclusivamente jurídicos, quer na letra expressa da lei quer na força que emana do seu conjunto sistemático, afasta-me de considerar a punição física dos responsáveis, o que desnaturaria, a meu ver, a natureza pétrea da lei de anistia (GREGORI, 2012, p. 7).

Piovesan (2012) não segue a mesma linha de interpretação, para a autora, o julgamento e punição a quem violou os direitos humanos no período abrangido pela lei da Comissão da Verdade são imprescindíveis.

A absoluta proibição da tortura, o direito à verdade e o direito à justiça estão consagrados nos tratados internacionais, impondo ao Estado brasileiro o dever de investigar, processar, punir e reparar graves violações a direitos humanos, especialmente em se tratando de crime internacional. (PIOVESAN, 2012, p. 7-8).

Apesar destas divergências em relação ao objetivo da Comissão da Verdade, é amplo o consenso sobre a importância da construção ou do resgate a uma verdade histórica, numa esfera internacional o Jurista francês Louis Joinet, destaca que o direito à verdade ou o direito de saber, é fundamental para a luta contra a impunidade das violações dos direitos humanos. Destaca a importância das comissões não judiciais de investigação, ou as Comissões de Verdade e Reconciliação. Além da preservação dos arquivos relativos às violações dos direitos humanos. 
Especialmente, quando de um processo de transição, o direito de saber implica que sejam preservados os arquivos. As medidas que devem ser tomadas para isso têm relação com os seguintes pontos: a) medidas de proteção e de repressão contra a subtração, a destruição ou a ocultação; b) realização de um inventário de arquivos disponíveis, que inclua os existentes em outros países com a finalidade de que, com sua cooperação, possam ser consultados ou, se for o caso, restituídos; c) adaptação à nova situação da regulamentação do acesso aos arquivos e de sua consulta, principalmente outorgando o direito a toda pessoa que seja imputada a garantia de seu direito à resposta e que esse seja incluído em seu dossiê (JOINET apud CUYA, 2011, p. 41).

No próximo tópico trabalha-se a partir das Comissões concluídas da Argentina e do Chile a relação entre informação, verdade e documento. As experiências dessas Comissões são o pano de fundo para uma abordagem da informação como construção de sujeitos competentes linguisticamente, onde sua principal função estaria intrínseca ao processo de aprendizagem.

\section{INFORMAÇÃO, VERDADE E DOCUMENTO}

Destaca-se na pesquisa as Comissões concluídas da Argentina e do Chile, como modelo para a recém-instaurada Comissão Nacional da Verdade do Brasil. O motivo da escolha desses países foi à similaridade entre os regimes ditatoriais, apesar das diferenças em seus métodos repressivos. Não obstante as diferentes nomenclaturas utilizadas pelas comissões investigadas, escolheu-se na pesquisa a intitulação de comissões da verdade pelo motivo de não ter-se enfatizado o objetivo fim das comissões, mas sim, o seu papel de aprendizagem.

Com isso, na Argentina a Comissão Nacional sobre o Desaparecimento de Pessoas foi criada por meio do Decreto o 187, de 19 de dezembro de 1983, pelo presidente constitucional Raúl Ricardo Alfonsín e teve como objetivo principal investigar o destino dos desaparecidos políticos durante a ditadura militar da Argentina, que perdurou entre os anos de 1976 e 1983.

Após nove meses de trabalho, a Comissão, identificada pela sigla CONADEP, reuniu mais de 50 mil páginas de testemunhos e denúncias e confeccionou o seu relatório final, intitulado, Nunca Más: informe de la Comisión Nacional sobre la Desaparición de Personas.

O principal legado dessa Comissão foi sua importante atuação no processo de redemocratização e reconstrução histórica e o reconhecimento de seus trabalhos pelas 
esferas pública e jurídica. Os depoimentos expostos em seu relatório ainda hoje servem como material para o debate na sociedade e como prova para julgamentos de pessoas responsáveis por violações de direitos humanos.

A atual presidente da Argentina, Cristina Elisabet Fernández de Kirchner, ofereceu acesso, em janeiro de 2010, aos arquivos confidenciais referentes à atuação das Forças Armadas na ditadura militar do país. Fundamentou-se no argumento de que a atuação das Forças Armadas durante a vigência do terrorismo de Estado demonstrou que a informação e a documentação, classificadas como confidenciais, não estiveram destinadas à proteção dos interesses legítimos próprios de um Estado democrático, mas, ao contrário, serviram para ocultar a ação ilegal do governo. Nesse sentido, manter o sigilo dos documentos seria contrário à política da memória, verdade e justiça. $\mathrm{O}$ decreto expressou casos judiciais que determinaram a reabertura de causas de violações de direitos humanos durante o período ditatorial.

No Chile, foram instauradas três comissões sendo a primeira a Comissão Nacional da Verdade e Reconciliação que foi criada pelo presidente Patricio Aylwin por meio do Decreto Supremo no 355, de 24 de abril de 1990, com o objetivo de contribuir para o total esclarecimento da verdade sobre as graves violações aos direitos humanos cometidas nos anos anteriores, no país ou no estrangeiro, caso tais violações estivessem relacionadas com o Estado do Chile ou com a vida política nacional. Sua finalidade era colaborar com a reconciliação de todos os chilenos, sem prejuízo dos procedimentos judiciais aos quais pudessem dar lugar tais atos.

Em 1992, complementando o trabalho dessa Comissão, o governo chileno criou, por meio da Lei oㅜ 19.123, a Corporação Nacional de Reparação e Reconciliação, para executar as recomendações da Comissão da Verdade e Reconciliação, especialmente na reparação material dos danos causados pela ditadura de Pinochet.

Em 2003, uma terceira comissão extrajudicial foi criada, denominada Comissão Nacional sobre Prisão Política e Tortura, a qual conseguiu o reconhecimento das vítimas do regime pelo Estado. Essa comissão conseguiu receber informações de cerca de 35.868 pessoas, vítimas diretas ou familiares diretos de pessoas falecidas, atualmente residentes no Chile e em outros 40 países do mundo. Ao concluir suas investigações, a Comissão reconheceu como vítimas de prisão política e tortura 28.459 pessoas, entre elas 3.621 mulheres e 1.244 menores de 18 anos. Essas vítimas obtiveram o direito de receber uma reparação do Estado. 
A comissão chilena sobre prisão política e tortura reconheceu, em seu relatório final, que os resultados do trabalho não teriam sido alcançados sem a colaboração de milhares de vítimas, que em muitos casos decidiram finalmente falar das experiências que nunca antes haviam comentado. Isso permitiu acabar definitivamente com a conspiração de silêncio sobre a tortura predominante por décadas no país.

No Brasil, a Comissão Nacional da Verdade foi criada pela Lei ํo 12.528/2011 e instituída em 16 de maio de 2012, pela presidente Dilma Rousseff. O número de colaboradores atualmente é de aproximadamente 50 pessoas, distribuídos entre servidores, estagiários e consultores.

A finalidade da comissão é examinar e esclarecer as graves violações de direitos humanos no período entre os anos de 1946 e 1988, com o objetivo final de efetivar o direito à memória e à verdade histórica e promover a reconciliação nacional. Cabe à comissão organizar, arquivar e manter o conjunto de requerimentos e documentos nela protocolizados, bem como preservar aqueles por ela produzidos, criando um acervo em homenagem à memória e à verdade histórica.

Com isso, descreve-se as atividades desenvolvidas até o momento pela Comissão. Em setembro de 2012, a Comissão definiu seu principal marco legal: por meio da sua resolução $n^{\circ}$ 2, que estabeleceu, de forma definitiva, que as graves violações de Direitos Humanos examinadas pela Comissão, são aquelas praticadas por agentes públicos. Um dos pilares para a decisão é a lei 9140/95, uma das que estabelecem as bases para o surgimento da Comissão Nacional da Verdade.

No mesmo mês, após recomendação da Comissão e atendendo solicitação da família Herzog, a Justiça de São Paulo determinou a mudança do registro de óbito de Vladimir Herzog para que a causa da morte do jornalista, em 1975, fosse alterada de asfixia mecânica para morte em decorrência de lesões e maus-tratos sofridos em dependência do II Exército - SP (Doi-Codi). A sentença de Vladimir Herzog abriu caminho para novas reivindicações de outras famílias vítimas do regime ditatorial.

A Comissão Nacional da Verdade desde julho de 2012 realiza audiências públicas e parcerias com outras comissões criadas no Legislativo e Executivo para colher depoimentos de vítimas de graves violações de Direitos Humanos ocorridas entre os anos de investigação desta Comissão, com destaque as violações ocorridas durante o regime militar brasileiro (1964-1985). 
Considera-se que a instauração da Comissão Nacional da Verdade, contribui para a aprendizagem no âmbito da esfera pública, ao incentivar o processo de busca de informação através do diálogo conduzido na esfera pública

A partir das citações expostas pode-se afirmar que a questão da verdade é um dos principais desafios dessas comissões, neste sentido, procura-se avaliar qual a relação entre 0 acesso às informações por meio dos atos de fala do testemunho e dos documentos que se originariam na esfera da ação comunicativa, os argumentos do discurso e a aprendizagem. Utiliza-se como marco teórico à reformulação do conceito de verdade por Habermas.

\section{VALIDAÇÃO A PARTIR DO DISCURSO}

Em seu primeiro trabalho sobre teorias da verdade, Habermas (2009) situa a idéia da verdade no domínio do resgate discursivo de pretensões de validade: "a idéia de verdade somente pode ser desenvolvida se pressupusermos o resgate discursivo de pretensões de validade." (HABERMAS apud SIEBENEICHLER, 2003, p. 99). Utilizando o modelo jurídico, pode-se definir uma pretensão de validade como uma pretensão que pode ser reclamada, ou seja, feita valer, pode ser contestada e defendida, rejeitada ou reconhecida. Pretensões são reconhecidas como válidas ou não válidas. Somente quando pode deduzir-se uma razão suficiente para o reconhecimento de uma pretensão de validade, que dizemos que esta é reconhecida porque e exclusivamente porque é legítima. Uma pretensão é legítima na medida em que pode ser sustentada. A validade legítima de uma pretensão garante a confiabilidade de que as expectativas resultantes de uma determinada pretensão serão satisfeitas.

Podemos elucidar o que é uma pretensão de validade com recurso ao modelo da pretensão jurídica. Uma pretensão pode ser reclamada, isto é, feita valer, pode ser contestada e defendida, rejeitada ou reconhecida. Pretensões que são reconhecidas são válidas. A circunstância de pretensões de validade realmente encontrarem reconhecimento pode ter muitos motivos (ou causas). No entanto, se e enquanto da "própria coisa" puder ser deduzido uma razão suficiente para o reconhecimento de uma pretensão de validade, dizemos que esta é reconhecida porque e exclusivamente porque é legítima (ou se afigura legítima aos que a reconhecem). Uma pretensão é designada por legítima se e na medida em que pode ser sustentada. É que a validade legítima de uma pretensão garante a fiabilidade com que as expectativas resultantes de uma determinada pretensão são satisfeitas (HABERMAS, 2009, p. 183). 
A teoria discursiva da verdade se apóia nas seguintes idéias, a saber: o quadro de referência entre ação comunicativa e discurso; a precedência das ações comunicativas voltadas para o entendimento sobre as ações estratégicas; o resgate discursivo teórico e prático de pretensões de validade. (SIEBENEICHLER, 2003, p.99). Neste trabalho, enfatizamos a referência entre a ação e o discurso visando investigar o papel da informação nestas esferas comunicativas.

Nesse sentido, na descrição das áreas comunicativas da ação e do discurso, Habermas (2009) assinala o papel da informação, o autor, faz uma analogia entre a informação e a experiência e aponta que a informação estaria apenas no âmbito da ação comunicativa.

\begin{abstract}
Sob o tópico "ação" introduzo a área comunicativa em que tacitamente pressupomos e reconhecemos as pretensões de validade implícitas às expressões (e igualmente às afirmações) a fim de trocarmos informações (ou seja, experiências referentes à ação). Sob o tópico "discurso" introduzi a forma de comunicação caracterizada pela argumentação em que pretensões de validade que se tornaram problemáticas são tematizadas e analisadas relativamente à sua legitimidade. Para levarmos a cabo discursos temos, de certo modo, de sair dos contextos da ação e da experiência; aqui não trocamos informações, mas sim argumentos destinados a fundamentarem (ou rejeitarem) pretensões de validade problematizadas. Discursos requerem, em primeiro lugar, uma suspensão de constrangimentos à ação que deve levar a que todos os motivos, com a única exceção da disposição cooperativa para o entendimento, possam ser revogados (e a que questões de validade possam ser separadas das de gênese) (HABERMAS, 2009, p. 184-185).
\end{abstract}

Sendo assim, Habermas (2009) afirma que os discursos necessitam de uma virtualização de pretensões de validade para que possamos assinalar perante objetos da experiência e das informações, ou seja, as certezas recorrentes nas afirmações de atores que se baseiam nas interações com os objetos do mundo objetivo devem ser tratadas de forma hipotética.

A partir desta diferenciação Habermas (2009) completa a questão desenvolvida pela teoria da redundância que é uma crítica da teoria da verdade por correspondência. "[...] em contextos de ação comunicativa, uma explicação da pretensão de validade feita valer com afirmações seria redundante; no entanto, é imprescindível em discursos, visto que estes tematizam a legitimidade de pretensões de validade." (HABERMAS, 2009, p. 185). 
Com isso, Habermas (2009) resgata uma nova questão associada a uma intuição da teoria da verdade por correspondência. Como se relacionam os fatos que afirmamos com os objetos da nossa experiência? A partir da ideia de Strawson (1959 apud HABERMAS, 2009, p. 185). Habermas (2009), afirma a seguinte definição, para fatos e objetos da experiência.

Aquilo que nos é lícito afirmar designamos por fato. Um fato é aquilo que torna um enunciado verdadeiro; por isso dizemos que os enunciados reproduzem, descrevem, exprimem fatos, e assim por diante. Coisas e acontecimentos, pessoas e respectivos enunciados, ou seja, objetos da experiência, são, por outro lado, aquilo sobre o que formulamos afirmações e sobre o que enunciamos algo: se a afirmação for legítima, aquilo que afirmamos dos objetos é um fato. [...]. Com objetos faço experiências, mas afirmo fatos; não posso ter uma experiência de fatos, nem afirmar objetos (ou experiências com objetos). Ao afirmar fatos posso apoiar-me em experiências e referir-me a objetos (HABERMAS, 2009, p. 185-186).

A teoria da verdade por correspondência erra ao supor que os enunciados verdadeiros correspondem a fatos, sendo que esta afirmação só tem sentido se os enunciados representarem algo no mundo de objetos reais. Entretanto, essa teoria, tem uma observação acertada a admissão dos objetos da experiência ou objetos reais. Em outra definição, pode-se dizer a admissão de um mundo suposto como objetivo.

Os fatos só aparecem na linguagem, na área comunicativa do discurso, e nos informamos a respeito dos objetos da experiência no âmbito da ação comunicativa. "No contexto de ação, a afirmação desempenha o papel de uma informação sobre uma experiência com objetos, ao passo que no discurso desempenha o papel de um enunciado com pretensão de validade problematizada." (HABERMAS, 2009, p. 188).

A partir disso, constata-se que no âmbito da teoria da verdade discursiva, a verdade não é uma propriedade de informações, mas sim de enunciados hipotéticos.

De informações dizemos que são fiáveis (ou não são fiáveis). A fiabilidade de uma informação afere-se pela probabilidade com que as expectativas de comportamento derivadas da mesma informação (em contextos de ação) são satisfeitas. Pode dar-se o caso de podermos explicitar a relação pragmática entre a cognição e os objetos da experiência com recurso ao conceito de correspondência (embora neste contexto não se possa descurar 0 fato de a objetividade da experiência se encontrar fundamentada em condições subjetivas e universais da possibilidade da experiência). A verdade, pelo contrário, não é uma propriedade de informações, mas sim de enunciados (HABERMAS, 2009, p. 189). 
Nessa teoria da verdade o entendimento obtido através da argumentação discursiva, pode ser tido como um critério de verdade, se este entendimento promover a continuidade da aprendizagem, o que consiste na abertura para o questionamento do outro e na possibilidade de alteração. A partir disso, se configura dois tipos de discursos, a saber: o discurso teórico no qual são tematizadas as pretensões de verdade controversas; e o discurso prático no qual é possível examinar hipoteticamente a pretensão de correção das normas e dos valores.

A teoria discursiva da verdade aponta uma condição para a comunicação voltada para o entendimento, esta condição é a situação ideal de fala. A situação ideal de fala constitui uma suposição ou antecipação contrafática que fazemos necessariamente sempre que entramos num processo discursivo argumentativo:

Designo por ideal uma situação de fala em que as comunicações não são obstruídas, não só por intervenções contingentes exteriores, mas igualmente por constrangimentos que derivam da própria estrutura da comunicação. A situação de fala ideal exclui distorções sistemáticas da comunicação. Mais concretamente, a estrutura comunicativa só não produz constrangimentos se para todos os participantes do discurso é dada uma distribuição simétrica das oportunidades de escolherem e levarem a cabo atos da fala. Desta exigência geral da simetria podem deduzir-se, para as diversas classes de atos da fala, exigências específicas de uma distribuição eqüitativa das oportunidades de escolher $\mathrm{e}$ levar a cabo atos da fala (HABERMAS, 2009, p. 227).

A situação de fala ideal pode ser tomada como critério da argumentação discursiva porque implica uma distribuição igualitária de chances de escolha e de realização de atos de fala. Supomos que nela não exista nenhum elemento de coação a não ser a coação do melhor argumento.

Com isso, constata-se que a teoria discursiva da verdade foi proposta a partir da virada lingüística como uma tentativa de sair do dilema da teoria da verdade por correspondência e oferecer a tentativa de combinar a compreensão de referência transcendente em relação à linguagem com uma compreensão, imanente à linguagem, de verdade como assertividade ideal.

Todavia, segundo Habermas (2004b, p.59), se afirmarmos que a verdade é uma possibilidade justificada de afirmação, desconsideraríamos um aspecto importante, "a verdade que afirmamos em uma proposição deve ser verdadeira sempre e para qualquer público". Apesar disso, mesmo as proposições bem justificadas podem ser consideradas 
falsas no futuro. Neste sentido, o conceito de verdade como assertividade ideal não considera a possibilidade de falibilidade de nossas justificações.

Por esse motivo, foram levantadas objeções convincentes a teoria discursiva da verdade e a idéia de que é verdadeiro aquilo que pode ser racionalmente aceito em circunstâncias ideais. Essas objeções se fundamentavam em parte contra dificuldades conceituais do estado ideal de fala e da justificação, e de outro lado, pelo caráter paradoxal da idéia de um consenso último ou a toda outra interpretação, "de modo que o que pretende ser a situação de entendimento mútuo ideal revela ser uma situação além da necessidade (e do problema) do entendimento mútuo lingüístico." (WELLMER, 1986 apud HABERMAS, 2004b, p. 252).

Com isso, Habermas (2004a), a partir da crítica ao contextualismo de Rorty, oferece um conceito de verdade duplo, no âmbito do mundo da vida e do discurso. Esse conceito de verdade se fundamenta no contexto das atividades cotidianas, a partir da necessidade dos atores de chegarem a um bom termo com o mundo, "eles não podem evitar ser realistas no contexto de seu mundo da vida. E eles têm o direito de sê-lo, pois seus jogos de linguagem e práticas, enquanto funcionam imunes a decepções, "resistem à prova" na própria execução." (HABERMAS, 2004b, p. 257).

Desse modo, o mundo da vida, com seus fortes conceitos de verdade e saber circunscritos à ação, penetra no discurso e fornece o ponto de referência que transcende justificações e mantém desperta entre os interlocutores a consciência da falibilidade de nossas interpretações. Inversamente, essa consciência falibilista reflui sobre a práxis, sem com isso destruir o dogmatismo do mundo da vida (HABERMAS, 2004b, p. 258).

As convicções têm um papel diferente na ação e no discurso, e também 'resistem à prova' de maneiras distintas em ambos os contextos. Na práxis, o pré-reflexivo 'chegar a um bom termo com o mundo' decide se as convicções 'funcionam' ou se caem no sorvedouro da problematização, enquanto na argumentação são apenas razões que revelam se pretensões de validade controversas merecem ou não um reconhecimento racionalmente motivado. Por certo, é apenas nesse nível reflexivo que se põe a questão acerca da conexão interna entre justificação e verdade; mas uma resposta a isso só é permitida pela interação entre ações e discursos. [...] Apenas o entrelaçamento dos dois diferentes papéis pragmáticos que 0 conceito de verdade bifronte desempenha em contextos de ação e discurso pode explicar por que uma justificação bem-sucedida em nosso contexto leva a pensar que uma opinião justificada é verdadeira independentemente do contexto. Tal como de um lado, o conceito de verdade permite traduzir as abaladas certezas de ação em enunciados problematizados, assim também manter a orientação pela verdade 
permite, de outro, retraduzir asserções discursivamente justificadas em certezas de ação restabelecidas (HABERMAS, 2004b, p. 258-259).

As práticas do mundo da vida são sustentadas por uma consciência plena de certeza que não deixa nenhum espaço para reservas quanto à verdade. $O$ comportamento solucionador de problemas processa as decepções que surgem contra 0 pano de fundo de expectativas estáveis, ou seja, no contexto de uma grande massa de concepções ingenuamente tidas por verdadeiras. No trato prático com um mundo objetivo suposto como idêntico e independente, os atores dependem de certezas de ação. E estas implicam, por sua vez, que se tenham as informações que governam a ação como absolutamente verdadeiras, mesmo que provisoriamente.

No âmbito do discurso, o modo performativo caracterizado por uma suposição incondicional de verdade é suspenso e transformado na ambivalência dos participantes de um discurso, onde, resgatam ou rejeitam pretensões de validade hipotéticas. Essa referência transcende a algo situado no mundo objetivo e lembra aos participantes que 0 conhecimento em pauta, surgiu em primeiro lugar do conhecimento das pessoas enquanto atores, neste sentido, eles não esquecem do papel transitório desempenhado pela argumentação no contexto do mundo da vida. Sendo assim, a relação intrínseca entre verdade e justificação é revelada pela função pragmática de conhecimento que oscila entre as práticas cotidianas e os discursos.

A relação intrínseca entre verdade e justificação é revelada pela função pragmática de conhecimento que oscila entre as práticas cotidianas e os discursos. Os discursos são como máquinas de lavar: filtram aquilo que é racionalmente aceitável para todos. Separam as crenças questionáveis e desqualificadas daquelas que, por um certo tempo, recebem licença para voltar ao status de conhecimento não-problemático (HABERMAS, 2004a, p. 63).

A exposição de forma descritiva das teorias da verdade desenvolvidas por Habermas teve como objetivo fundamentar as relações defendidas nesta investigação, quanto às informações como verdades provisórias no contexto das Comissões da Verdade investigadas e também na esfera pública dos países que instauraram estas Comissões. Além de estabelecer a partir da teoria de Habermas o papel da informação no processo de aprendizagem no âmbito das formas de validação destas informações por atores que agem intersubjetivamente por meio da linguagem. 
Conforme exposto anteriormente, constata-se que a origem do conhecimento que fundamenta as comissões da verdade está no âmbito do acesso a documentos e atos de fala dos concernidos ao período repressivo. Sendo assim, convenciona-se que tais informações estão inseridas na esfera da ação comunicativa. Habermas (2009), em seus estudos teóricos anteriores à teoria do agir comunicativo, descreve a diferença entre as esferas da ação comunicativa e do discurso. E afirma que as informações e as experiências, só agiriam na esfera da ação comunicativa.

Com isto, evidencia-se que as manifestações caracterizadas como informações e experiências de um mundo da vida não podem ser asseguradas de outra forma que não seja por meio do discurso. Por esse motivo González de Gómez (2008) afirma que a verdade não é um atributo da informação e cita a dificuldade de se acoplar à compreensão de uma referência transcendente à linguagem e a compreensão da verdade como imanente à linguagem. Segundo González de Gómez (2008), a abordagem sobre o desacoplamento e complementaridade entre informação e argumentos acarretaria nos seguintes problemas:

\footnotetext{
Em primeiro lugar, o problema da interdependência e assimetria entre garantias performáticas e garantias argumentativas, o qual se adensa, sob outra figura, em torno do problema da justificação e dos limites da aceitabilidade como critério de verdade. A principal dificuldade seria como acoplar a compreensão de uma referência transcendente a linguagem e a compreensão da verdade como imanente à linguagem, como assertividade ideal. Para Habermas, 'Um enunciado verdadeiro seria aquele que resiste a todas as tentativas de invalidação sob os pressupostos [pleno] pragmáticos dos discursos racionais, ou seja, que pudesse ser justificado numa situação epistêmica ideal' (GONZÁLEZ DE GÓMEZ, 2008, p. 10).
}

Contudo, a partir da revisão de Habermas de um conceito de verdade epistêmico, proveniente da teoria discursiva, para um conceito de verdade pragmático engastado nos dois contextos comunicativos, da ação e do discurso. Propõem-se abordar as evidências e as informações embutidas no mundo da vida, como verdades provisórias para fins pragmáticos.

Segundo Habermas (2007), esta abordagem dupla da verdade ocorre devido a todos os discursos estarem inseridos no mundo da vida. "Uma vez que os discursos permanecem enraizados no mundo da vida, existe um nexo interno entre os dois papéis 
que a idéia da orientação pela verdade assume aqui e lá - nas figuras de certezas de ação e em pretensões de validade hipotéticas." (HABERMAS, 2007, p. 43-44).

Além disso, a característica dupla da verdade, a partir da suposição de um mundo objetivo comum, é ampliada pelo reconhecimento de um público, ou nesta investigação, pelo reconhecimento da esfera pública.

A suposição de um mundo comum de objetos existentes independentemente dos quais podemos predicar fatos é completada com o auxílio da ideia de verdade como característica "não desperdiçável" dessas asserções. No entanto, se as asserções falíveis não puderem ser confrontadas diretamente com o mundo, necessitando, para sua fundamentação ou refutação, de outras afirmações e se, além disso, não houver nenhuma base de afirmações pura e simplesmente evidentes, isto é, credenciadas por si mesmas, então o único caminho para examinar pretensões de verdade passa a ser o discursivo. Em decorrência disso, a relação bipartida da validade de asserções é ampliada passando a ser uma relação tripartida de validade que afirmações têm "para nós". Sua verdade precisa ser reconhecível por um público (HABERMAS, 2007, p. $54)$.

A partir dessas ponderações, constata-se que as comissões da verdade se constituem como um local de um inter-relacionamento entre a esfera comunicativa da ação, na qual atuariam as informações e as evidências do mundo da vida e do discurso, aonde a validação da verdade é proveniente das razões e dos argumentos.

Contudo, é importante uma consideração, atenta-se que o processo de verdade não se fecha no âmbito das Comissões, mas, se caracteriza como uma dinâmica constante no contexto da Esfera Pública, que, segundo Habermas (2003), é o local, no qual, as pessoas privadas se reúnem em público e produzem deliberações sobre assuntos comuns, ou uma arena institucionalizada de interação discursiva, independente do Estado. Neste sentido, corrobora-se com a intuição da possibilidade de falibilidade das nossas afirmações, mesmo a partir dos discursos.

$\mathrm{Na}$ qualidade de espíritos finitos, não podemos prever a modificação de condições epistêmicas e por isso não podemos excluir a possiblidade de que uma afirmação, por mais que esteja justificada idealmente, possa vir a ser desmascarada como falsa. Entretanto, mesmo que se leve em conta tais objeções contra uma versão epistêmica do conceito de verdade, a ideia de um processo de argumentação, possivelmente inclusivo e retomável a qualquer momento, continua desempenhando uma função importante para a explicação da "aceitabilidade racional" - mesmo que não seja mais da "verdade". Porquanto nós, seres falíveis e situados no mundo da vida, não possuímos outro caminho para nos certificarmos da verdade 
que não seja o do discurso que é, ao mesmo tempo, racional e aberto ao futuro (HABERMAS, 2007, p. 54-55).

Sendo assim, considera-se que as informações provenientes da ação comunicativa são verdades provisórias, necessárias aos fins pragmáticos do mundo da vida, no qual se inserem as Comissões da Verdade, assim como os seus relatórios finais, que apesar de se basearem numa esfera argumentativa, são passíveis de falha no confronto com o mundo suposto como objetivo e assim transformam-se também em verdades provisórias numa dinâmica constante.

Nesta perspectiva, relacionam-se as ações informativas, inseridas nas comissões a partir dos testemunhos e dos documentos, como uma verdade provisória, que mantém sua relação com o mundo suposto como objetivo por uma necessidade prática. Não existiria possibilidade do discurso a respeito das violações se as certezas quanto aos fatos não fossem tidas como verdadeiras.

\section{CONSIDERAÇÕES FINAIS}

O presente artigo teve como objetivo evidenciar primeiramente que um dos principais fatores que fundamenta a instalação das comissões da verdade é promover aprendizagem no âmbito social. Esta aprendizagem se fundamenta no agir de atores sociais que visam o entendimento, orientados pela verdade. A partir disso, investigou-se 0 processo de aprendizagem no domínio das comissões instaladas nas novas democracias da América Latina, que se caracterizam por terem passado por períodos ditatoriais entre os anos de 1960 e 1980. Destacou-se a comissão recém-instaurada no Brasil, denominada como Comissão Nacional da Verdade.

A partir dessas comissões, procurou-se demonstrar o papel da informação no processo de aprendizagem e utilizou-se como fundamentação teórica à reformulação do conceito de verdade discursiva para o conceito de verdade pragmática. Com isso, constatou-se que as informações materializadas em atos de fala e documentos serviriam nestas comissões como verdades provisórias para seus fins pragmáticos e como referência para o discurso.

Nesse sentido, analisou-se o que legitima em um primeiro momento os atos de fala e documentos no âmbito das comissões da verdade e constatou-se que o primeiro fator que legitima estas informações é a sua relação com um mundo suposto como objetivo. 
Nesse sentido, estas informações são validadas primeiramente por serem evidências das violações de direitos humanos sofridas pelas vítimas destes regimes repressivos. Entretanto, estas evidências se validam no âmbito das comissões de maneira provisória, com fins de manter uma prática performática necessária às comissões. Sendo assim, constatou-se que a certificação da verdade não está no âmbito aproximadamente ideal das comissões da verdade, mas sim, na amplitude do discurso público promovido por estas comissões e gerador de aprendizagem.

Com isso, evidenciou-se que a reformulação do conceito de verdade abre uma nova possibilidade para a abordagem da informação no contexto das práticas de atores sociais, a informação se evidencia como uma ligação entre o mundo suposto como objetivo e o discurso.

\section{REFERÊNCIAS}

ARGENTINA. Comisión Nacional Sobre la Desaparición de Personas. Nunca más. Buenos Aires: EUDEBA, 1995.

Decreto no 187, de 15 de diciembre de 1983. Crea a Comisión Nacional sobre la Desaparición de Personas. Boletín Oficial. 19 Dic. 1983.

BRASIL. Comissão nacional da verdade. Disponível em: <http://www.cnv.gov.br/>. Acesso em: 10 fev. 2013.

Lei no 12.528, de 18 de novembro de 2011. Cria a Comissão Nacional da Verdade no âmbito da Casa Civil da Presidência da República. Diário Oficial [da] República Federativa do Brasil. Poder Executivo, Brasília, 18 nov. 2011.

CHILE. Corporación Nacional de Reparación y Reconciliación. Informe de la comisión nacional de verdad y reconciliación. Chile, 1996. t. 1-2.

. Decreto Supremo no 355, de 24 de abril de 1990. Informe de la Comisión

Nacional de Verdad y Reconciliación. Chile, 1996. t. 1-2.

. Ley no19.123 del 8 de febrero de 1992. Informe de la Corporación Nacional de Reparación y Reconciliación. Chile, 1996.

CUYA, Esteban. Justiça de transição. Acervo, Rio de Janeiro, v. 24, n. 1, p. 37-78, jan./jun. 2011.

GONZÁLEZ DE GÓMEZ, Maria Nélida. Habermas, informação e argumentação. In: COLÓQUIO HABERMAS, 5., 2008, Florianópolis. Anais... Florianópolis: UFSC, set. 2008. p. 1-19. 
GREGORI, José. Comissão da verdade: mais um elo de uma corrente. Interesse Nacional, São Paulo, ano 5, n. 17, p. 9-13, abr./jun. 2012.

HABERMAS, Jürgen. Entre naturalismo e religião: estudos filosóficos. Rio de Janeiro: Tempo Brasileiro, 2007.

A ética da discussão e a questão da verdade: estudos de teoria política. 3. ed. São Paulo: Martins Fontes, 2004a.

Mudança estrutural da esfera pública: investigações quanto a uma categoria da sociedade burguesa. 2. ed. Rio de Janeiro: Tempo Brasileiro, 2003.

Pensamento pós-metafísico: estudos filosóficos. Rio de Janeiro: Tempo Brasileiro, 2002.

Teoria da racionalidade e teoria da linguagem. Lisboa: Ed. 70, 2009. (Obras escolhidas de Jurgen Habermas, v. 2).

Verdade e justificação: ensaios filosóficos. São Paulo: Loyola, 2004b.

NAÇÕES UNIDAS. Instrumentos del Estado de Derecho para sociedades que han salido de um conflicto: comissiones de la verdade. Nova lorque/Genebra: ONU, 2006.

PIOVESAN, Flávia. Direito à verdade e à justiça: o caso brasileiro. Interesse Nacional, São Paulo, v. 5, n. 17, p. 14-24, abr./jun. 2012.

SIEBENEICHLER, Flávio Beno. Jurgen Habermas: razão comunicativa e emancipação. Rio de Janeiro: Tempo Brasileiro, 2003.

WINAND, Erica Cristina Alexandre; BIGATÃO, Juliana de Paula. A política brasileira para os direitos humanos e sua inserção nos jornais: a Comissão Nacional da Verdade. In: CONGRESSO DA ASSOCIAÇÃO DE ESTUDOS LATINO-AMERICANOS, 2012, San Francisco. Anais... San Francisco, 2012. p. 1-24.

\section{Title}

Truth commission: the documents and the validity of the speech

\section{Abstract}

Introduction: This article is based on the dissertation, the Truth Commission: the documents and the validity of the speech, defended the Brazilian Institute of Information in Science and Technology in 2013 , aims to investigate the role of information, embodied in documents, from the action of social actors who act communicatively and produce learning act.

Objective: To investigate the role of information, embodied in documents from the action of social actors who act communicatively and produce learning act. It is used as an object of research National Truth Commission of Brazil. 
Methodology: The methodology used is a descriptive and exploratory. It is used as a theoretical reformulation of a discursive version of the truth made by Jürgen Habermas for the purpose of remedying the problem of inefficiency of correspondence theory of truth.

Results: In this theory the concept of truth is compared to an ideal and assertiveness of the attribute is set.

Conclusion: From the pragmatic theory of truth is evident, the object of study, that the information in speech acts and their materialization documentary acts as a temporary truth that validates the public discourse.

Keywords: Habermas. Truth commission. Information. Document. Truth. Speech.

\section{Título}

Comisión de la verdad: los documentos y la validez del discurso

\section{Resumen}

Introducción: Este artículo se basa en la tesis, la Comisión de la Verdad: los documentos y la validez del discurso, defendió el Instituto Brasileño de Información en Ciencia y Tecnología en 2013, tiene como objetivo investigar el papel de la información, consagrado en los documentos, de la acción de los actores sociales que actúan comunicativamente y producen acto de aprendizaje.

Objetivo: Para investigar el papel de la información, consagrado en los documentos de la acción de los actores sociales que actúan comunicativamente y producen acto de aprendizaje. Se utiliza como un objeto de investigación de la Comisión Nacional de la Verdad de Brasil.

Metodología: La metodología utilizada es de tipo descriptivo y exploratorio. Se utiliza como una reformulación teórica de una versión discursiva de la verdad hecha por Jürgen Habermas con el fin de remediar el problema de la ineficiencia de la teoría de la verdad como correspondencia.

Resultados: En esta teoría el concepto de verdad se compara con un ideal y la asertividad del atributo está establecido.

Conclusiones: A partir de la teoría pragmática de la verdad es evidente, el objeto de estudio, que la información de los actos de habla y sus actos documentales materialización como una verdad temporal que valida el discurso público.

Palabras clave: Habermas. Comisión de la verdad. Información. Documento. Verdad. Discurso.

Recebido em: 10.09.2013

Aceito em: 30.11.2013 